\title{
Progress on RNAi-based molecular medicines
}

This article was published in the following Dove Press journal:

International Journal of Nanomedicine

25 July 2012

Number of times this article has been viewed

\section{Jing Chen}

Jianping Xie

Institute of Modern

Biopharmaceuticals, State Key

Laboratory Breeding Base of Ministry

of Education Eco-Environment of

the Three Gorges Reservoir Region,

School of Life Sciences, Southwest

University, Chongqing, China
Correspondence: Jianping Xie Institute of Modern Biopharmaceuticals, State Key Laboratory Breeding Base of Ministry of Education Eco-Environment of the Three Gorges Reservoir Region, School of Life Sciences, Southwest University, Chongqing 4007I5, China Tel +862368367108

$\mathrm{Fax}+862368367108$

Email georgex@swu.edu.cn
Abstract: RNA interference (RNAi) is a promising strategy to suppress the expression of disease-relevant genes and induce post-transcriptional gene silencing. Their simplicity and stability endow RNAi with great advantages in molecular medicine. Several RNAi-based drugs are in various stages of clinical investigation. This review summarizes the ongoing research endeavors on RNAi in molecular medicine, delivery systems for RNAi-based drugs, and a compendium of RNAi drugs in different stages of clinical development. Of special interest are RNAi-based drug target discovery and validation, delivery systems for RNAi-based drugs, such as nanoparticles, rabies virus protein-based vehicles, and bacteriophages for RNA packaging.

Keywords: RNA interference, delivery systems, liposome, nanoparticle, molecular medicines

\section{Overview of RNA interference}

RNA plays key roles in organisms beyond the traditional role of being a messenger bridging genetic information and biosynthesis of protein. Endogenous or exogenous double-stranded RNA can be cleaved into 21-23-nucleotide small interfering RNA (siRNA) by the endonuclease, Dicer. siRNA can unzip into a guide strand and a passenger strand. The latter will be subsequently degraded. The guide strand is then incorporated into the RNA-induced silencing complex and binds to the target mRNA, inducing mRNA degradation by Argonaute, a component of the RNA-induced silencing complex which affects protein synthesis (Figure 1). This phenomenon is known as RNA interference (RNAi) ${ }^{1-4}$ and is well established in diverse organisms.

There are three major types of small RNA used to silence gene function by RNAi technology, ie, microRNA (miRNA), siRNA, and short hairpin RNAs (shRNA), 5,6 Although all small RNAs are 22-24 nucleotides in length, ${ }^{7-9}$ there are some important differences between them. First, siRNA, processed from exogenously introduced strictly base-paired siRNA duplexes, are completely complementary to their target mRNA and facilitate cleavage of bases 10-12 at the $5^{\prime}$ end of the guide strand, ${ }^{10,11}$ resulting in transient silence of the target gene. Second, shRNA, inserting in a Pol III expression cassette, can be transfected or packaged into a recombinant virus and introduced into target cells. ${ }^{5}$ The advantage of shRNA is prolonged expression of the RNAi effect. Third, miRNA or chimeric miRNA/shRNA, derived from endogenously encoded shRNAs, ${ }^{5}$ can mediate gene silencing post-transcriptionally, and bind partially to complementary miRNA target sequences located in the $3^{\prime}$ untranslated regions of target mRNAs, ${ }^{9}$ but the "seed" region located in bases $2-8$ is highly complementary. ${ }^{12}$ The seed region can 


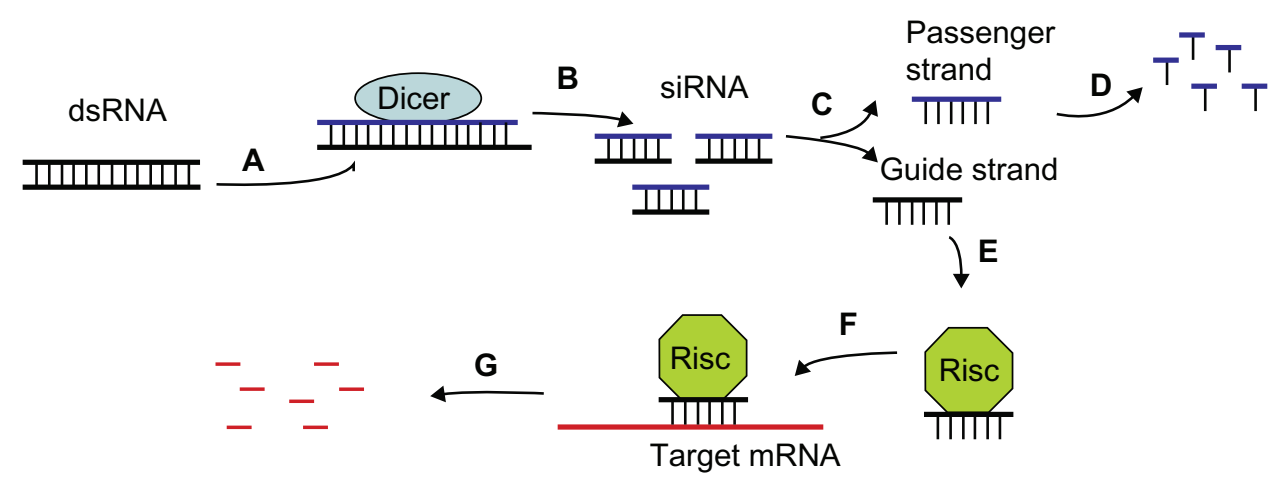

Figure I Schematic representation of RNAi. (A and B) Double-stranded RNA is cleaved into siRNA by Dicer. (C and D). siRNA is unzipped into a guide strand and passenger strand. The latter is subsequently degraded. (E-G). The guide strand is incorporated into a RISC and binds to target mRNA, inducing degradation of mRNA. Abbreviation: RISC, RNA-induced silencing complex.

result in deadenylation, translational repression, and decay of mRNAs. ${ }^{9,13,14}$ Interestingly, either strand of miRNA can silence gene expression post-transcriptionally ${ }^{6}$ and some translational repression mediated by miRNA is reversible. ${ }^{15}$ miRNA are the latest major breakthrough in the field of RNAi and represents an important tool for RNAi to overcome some of the limitations of shRNA. 5

\section{RNAi as a tool for discovery of drug targets}

Most drugs function via blocking of their targets. The simplicity and stability of RNAi in gene silencing make it a powerful tool in drug research and development. ${ }^{16}$ RNAi-based drug target discovery includes the following steps.

\section{Identification of target genes}

The selection of target gene is crucial and, to great extent, determines whether subsequent RNAi silencing can be effective or not. The abundance of the target gene, the regulation of its expression, and the half-life of its products are several important parameters that should be factored into. ${ }^{17}$ For example, mutation of somatic cells and their unchecked proliferation are the main factors underlying tumors. Based on this phenomenon, the RNAi library and high throughput screening can be harnessed to find the genes or proteins involved in tumor development to pinpoint drug target candidates. $^{18}$

\section{Designing siRNA}

Once the target is defined, siRNA can be used to evaluate potential candidates. siRNA-mediated target RNA cleavage is highly sequence-specific. Any mismatches in the siRNA duplex can abolish potential target RNA cleavage. ${ }^{17}$ Therefore, the success of RNAi-based therapeutics is strictly dependent on siRNA which can silence target genes specifically and effectively. There are various online algorithms available for appropriate design of siRNAs. ${ }^{5}$ Some empirical characteristics of efficacious siRNA are summarized as follows:

- $\mathrm{G} / \mathrm{C}$ content should be relatively low, ${ }^{17,19}$ ranging between $30 \%$ and $52 \%,{ }^{19}$ because a high $\mathrm{G}$ content tends to form G quartet structures ${ }^{17}$

- Low internal stability of siRNA at the $5^{\prime}$ antisense end is a prerequisite for effective silencing; ${ }^{19}$ internal repeats or palindromes in siRNA sequences may form internal fold structures; ${ }^{19}$ the silencing potential and effective concentration of siRNA can be reduced by these hairpinlike structures ${ }^{19}$

- Silencing efficiency is inversely proportional to high internal repeat stability ${ }^{19}$

- The sense strand has an A at positions 3 and 195,19,20

- The sense strand has a $U$ at position $10^{5,19,20}$

- The sense strand lacks a G or C at position $19^{19}$

- The sense strand lacks a $\mathrm{G}$ at position 13.5,19

The efficiency of siRNA can be improved if the abovementioned criteria are met.

\section{Constructing an RNAi library}

A library of artificial RNAi can induce RNAi to suppress expression of diverse genes. An RNAi library can be specific or random. A specific RNAi library is designed according to known genes, whereas a random RNAi library consists of random DNA fragments obtained by cleaving genomic DNA in specific reaction conditions. ${ }^{21}$ RNAi libraries have very much facilitated RNAi drug research.

\section{SiRNA-transfected target cells}

RNAi-based screening has singled out numerous candidate cancer targets, among which many have been or will be 
validated by disease-relevant in vitro phenotypic assays. However, few have been validated in vivo, largely due to the lack of effective vehicles and high cost. ${ }^{16}$ siRNA has been shown to be effective in several localized disease models. However, weak stability and low transmission efficiency during in vivo delivery have severely limited its application. ${ }^{16}$

The "off-target" effect of RNAi is a severe drawback. To realize the benefit of RNAi fully, this effect must be eliminated or minimized. ${ }^{16}$ An ideal drug target would have high on-target efficacy and low toxicity. ${ }^{5}$ Generally, toxicity is caused by saturation of the endogenous RNAi machinery following transfection of siRNA or expression of shRNA. Reducing the intracellular concentration and/or cell-specific expression of shRNA can minimize side effects. ${ }^{5,22}$ This can be achieved by using a regulated RNAi expression cassette delivered either by a nonviral or a viral vector. ${ }^{5}$ The delivery vehicle is crucial to achieve the above goal and should be capable of circumventing the reticuloendothelial system, be effectively taken up by the target tissues, and be able to escape from the endosome after endocytosis. ${ }^{23}$

\section{Expression cassette for RNAi}

Under the control of RNA polymerase III promoters, the expression of shRNA can introduce siRNA into cells. ${ }^{22,24,25}$ Heritable gene knockdown can be achieved by incorporating the shRNA cassette into viral vectors in cells and even in whole animals. ${ }^{22,26-28}$ Inducible systems which silence RNA expression by RNA polymerase III promoters containing operator sequences (tetO) of the Escherichia coli tetracycline resistance (tet) operon ${ }^{22}$ have been developed. ${ }^{29}$ This tetracycline-inducible gene regulation system has become a powerful device for transient and dose-dependent regulation of target gene expression in vitro and in vivo. ${ }^{30} \mathrm{~A}$ lentiviral based-system in which a tetO sequence is located between the $\mathrm{H} 1$ promoter and shRNA was developed. This system can cooperate with another cassette consisting of the codonoptimized tetR ${ }^{31,32}$ fused with enhanced green fluorescent protein by the T2A peptide under the control of the ubiquitin promoter, ${ }^{33}$ which can be used to treat type 2 diabetes mellitus. ${ }^{22}$ In the absence of the doxorubicin inducer, tetR binding to tetO can block shRNA transcription. Addition of doxorubicin or tetracycline can release tetR, thereby facilitating initiation of shRNA expression. ${ }^{22}$

\section{Delivery systems}

Nanoparticles have recently been recognized as a principal delivery vehicle for gene therapy. ${ }^{34}$ Nanotechnology holds great promise for medicines for a number of reasons, ie, multiple selectivity, desirable solubility, and permeability, a favorable pharmacokinetic profile, tunable tissue specificity, higher stability under physiological conditions, and ready scale-up during manufacture..$^{35,36}$ Polymers are the basis of nanomedicine and their characteristics are constantly being improved to achieve better efficacy. Polymers can protect siRNA from serum nuclease degradation and escort the siRNA to the desired cells. ${ }^{37}$ One drawback of synthetic nanoparticles is their relatively lower transfection efficiency. ${ }^{38}$ This can be improved by modification. The primary, secondary, and tertiary amines within the cationic polymer polyethylenimine (PEI) enable it to complex with DNA or siRNA, creating a "proton sponge effect", 37,39 which can result in accumulation of PEI-siRNA complexes in the liver, lung, spleen, and kidney, and also in severe cytotoxicity, which limits its wider application. ${ }^{37}$ Poly(ethylene glycol) (PEG)-modified PEI polymers can reduce this adverse effect, and achieve higher transfection efficiency, more solubility and stability, and a longer circulation time in vivo, as well as fewer nonspecific interactions with serum protein. ${ }^{40}$ An example of this is a PEG-PEI/siRNA nanoparticle targeting CD44v6, a risk factor for lymph node metastasis and highly expressed in patients with gastric cancer and liver metastasis. ${ }^{41,42}$ The morphology of the PEG-PEI/siRNA nanoparticle has been monitored by scanning electron microscopy, and the size and surface charge of the nanoparticle assessed by zeta potential measurement. The transfection efficiency, cytotoxicity, and interactions with the target were measured using SGC7901 human gastric carcinoma cells as a model. The results showed that the N/P charge ratio between the PEG-PEI amino groups and the siRNA phosphate groups largely determines the transfection efficiency. The peak transfection efficiency of the PEG-PEI/siRNA nanoparticle was $72.53 \% \pm 2.38 \%$ at an N/P of 15, and the cytotoxicity of PEG-PEI was lower than that of PEI using the MTT assay. Optimal silencing of CD44v6 expression was achieved at a PEG-PEI/siRNA $\mathrm{N} / \mathrm{P}$ ratio of $15 .{ }^{40}$ More recently, nanoparticle-based delivery systems have largely been viral or nonviral. ${ }^{5}$

\section{Viral delivery systems}

Viruses can integrate shRNA expression cassettes into the genome, thereby inducing prolonged gene silencing. Viruses can be customized to specific tissue tropism. ${ }^{37}$ Delivery systems based on retrovirus, lentivirus, adenovirus, and adenovirus-related vectors have been validated in transgenic systems. ${ }^{38}$ They have the advantages of delivering siRNAs to nondividing cells and of improving biosafety by diminishing 
the risk of producing replication-competent viruses and evading dysregulation of endogenous genes by promoters and viral enhancers. ${ }^{43-45}$

Lentiviral vectors, in contrast with adenovirus, can introduce short RNA into bone marrow cells and blood, ${ }^{46}$ and are widely used in the biomedical field. Amyotrophic lateral sclerosis is a fatal and incurable degenerative disorder of motor neurons in the brainstem, spinal cord, and motor cortex, leading to generalized weakness and muscle atrophy. ${ }^{47}$ Amyotrophic lateral sclerosis has a high incidence of approximately 6/100,000, and about $90 \%$ of cases are sporadic, with the remaining $10 \%$ being familial. ${ }^{47}$ About $20 \%$ of familial cases arise from mutations in the $\mathrm{Cu} / \mathrm{Zn}$ superoxide dismutase (SDS1) gene. $S O D 1^{\mathrm{G} 93 \mathrm{~A}}$ and $S O D 1^{\mathrm{mis}}$ mutants were designed as a control for $S O D 1$ silencing, and a specific shRNA (shSOD1) was applicable to most mutant SOD1 proteins. In transgenic $S O D 1^{\mathrm{G} 93 \mathrm{~A}}$ mice, intraspinal injection of a lentiviral vector (LV-shSOD1) led to a longlasting and substantial decrease in mutant SOD1 protein, thereby delaying the onset and progression of amyotrophic lateral sclerosis. ${ }^{47}$

The transmissible spongiform encephalopathies or prion diseases are fatal neurodegenerative disorders prevalent among sheep, cattle, cervids, and humans. Transmissible spongiform encephalopathies arise from a cellular prion protein which misfolds and forms a protease-resistant isoform. The cellular prion protein is widespread among mammalian cells, and is highly expressed on glial and neuronal cells in the central nervous system. ${ }^{48,49}$ Prions migrate to the central nervous system, where a conformational change in the cellular prion protein causes a protease-resistant isoform. ${ }^{50}$ Decreasing the cellular prion protein in mice infected with transmissible spongiform encephalopathy can reduce the incidence and severity of the disease, delay its development, ${ }^{51,52}$ and even reverse its pathological progression. ${ }^{53}$ RNAi can effectively knock down the cellular prion protein in mice, but the effect on the outcome of prion disease remains to be determined.$^{54}$ Lentiviral vectors encoding prion proteinspecific shRNAs can be injected intracranially to knock down cellular prion protein expression, ${ }^{52}$ but the clinical application of this delivery method is limited due to irreversibility of cellular prion protein suppression. ${ }^{55}$

The chemokine receptor CCR5, a human immunodeficiency virus-type 1 (HIV-1) coreceptor, is essential for CCR5 tropic HIV-1 infection and serves as a desirable therapeutic target for inhibiting HIV-1. ${ }^{56-59}$ Hindering CCR5 expression protects against HIV-1 infection at the primary stage of the life cycle of the virus. $\triangle 32 C C R 5$, mutants with a 32-bp deletion in the CCR5 gene, do not express CCR5 and are highly effective in preventing HIV-1 infection. ${ }^{60,61}$ Therefore, it is a promising strategy for reducing CCR5 expression in a stable manner when treating HIV-infected patients. ${ }^{62}$ A hu-BLT (bone marrow/liver/thymus humanized) mouse model showed that engraftment of lentiviral vector-mediated CCR5 shRNA led to stable and efficient CCR5 knockdown in multiple lymphoid organs, and CCR5 expression was downregulated in systemic lymphoid organs without causing obvious adverse effects. ${ }^{62}$ In addition, the anti-HIV drug, BLT-HIV (rHIV7-shl-TAR-CCR5RZ) produced by Benitec Ltd, using lentivirus as a delivery tool has now entered into Phase Ib investigation.

The major drawbacks of viruses are their ready elimination by preexisting bloodstream antibodies, and their role in raising cytoxicity. Furthermore, viruses can activate coagulation or complement factors, and can induce neutralizing antibody responses that prevent repeated administration.

\section{Nonviral delivery systems}

The advantages of nonviral delivery systems, compared with viral vectors, are their ease of synthesis, low toxicity, and limited immune response. ${ }^{63}$ Nonviral vectors mainly contain liposomes and bacteriophages. ${ }^{37}$

\section{Liposome delivery systems}

The delivery systems based on liposomes can protect the nuclease, penetrate the cell membrane, and deliver RNA to target cells. ${ }^{38}$ This method can decrease immunogenicity and is much safer. ${ }^{64}$ Well designed lipid delivery systems can bypass the endosome and release siRNA. The endosomal pathway is the main obstacle to drug delivery into the cytoplasm. siRNA can be released by neutralization. ${ }^{38}$

More recently, a transvascular method which delivered siRNA across the blood-brain barrier by intracranial injection was reported. ${ }^{65}$ The siRNA was fused to a short peptide of the rabies virus glycoprotein which can bind to acetylcholine receptors on neuronal cells, ${ }^{66}$ and nine d-arginines were added to the C-terminal of the short peptide (RVG-9r), enabling it to interact electrostatically with siRNA. In this way, siRNA has been successfully delivered to neurons within the mouse brain and been shown to inhibit protein expression and protect against viral encephalitis. RVG-9r peptide within cationic liposomes can knock down cellular prion protein expression and dramatically decrease expression of the protease-resistant isoform in neurons infected with transmissible spongiform encephalopathy in vitro. ${ }^{55}$ This combination integrates the advantages of resistance 
of cationic liposomes to serum degradation and the target specificity of the RVG-9r peptide.

Stable nucleic acid-lipid particles (SNALPs) developed by Tekmira Pharmaceuticals, represent an efficacious siRNA delivery system. SNALPs are composed of a lipid bilayer containing a mixture of fusogenic and cationic lipids that enable cellular uptake and endosomal release of a nucleic acid payload. SNALPs can also be coated with a diffusible PEGlipid conjugate providing a neutral or hydrophilic surface, and stabilizes the particle during formulation. The exterior coating also shields the cationic bilayer in vivo, blocking rapid systemic clearance. ${ }^{67}$

In the study of hepatitis B virus (HBV), HBV263 is a siRNA molecule of HBV. HBV263M that placed one ribonuleotide on the $5^{\prime}$ end of the antisense strand of HBV263 was incorporated into lipid nanoparticles to form SNALPs. ${ }^{67}$ HBV263M-SNALP was intravenously injected into mice carrying replicating HBV to evaluate its biodistribution, halflife, immunostimulatory properties, and efficacy. The results showed that HBV263M-SNALP had improved efficacy and a longer half-life, and reduced serum HBV DNA to $>1.0 \log _{10}$ after three days of intravenous injections at a dose of $3 \mathrm{mg} / \mathrm{kg} /$ day. Furthermore, HBV263M-SNALP reduced toxicity, dosing frequency, and immunostimulatory side effects, and had more robust and persistent biological activity ${ }^{67}$ SNALP delivery systems for SNALP-apolipoprotein B and ALN-TTR01 have been used in several clinical trials due to their advantages.

\section{Gold nanoparticle delivery systems}

Excellent biocompatibility and easy surface chemistry make gold nanoparticles one of the most widely investigated nanomaterials, and they have received increasing attention in a wide range of biomedical fields, ${ }^{68}$ including radiotherapy, photothermal cancer therapy, biomolecular sensing, drug delivery, imaging, and regulation of DNA. ${ }^{69-71}$ Gold nanoparticles have emerged, especially in drug delivery, as promising candidates because of their excellent biocompatibility, high surface-to-volume ratio, versatility in synthesis, optical properties, and easy surface functionalization..$^{70,71}$

Until recently, diverse types of gold nanoparticles, including antisense oligonucleotide, plasmid DNA, and siRNA, have been explored for their ability to deliver nucleic acid drugs into cells. ${ }^{71-78}$ Cationic lipid-coated gold nanoparticles have been developed for efficient intracellular delivery of therapeutic siRNA. In this system, gold nanoparticles served as a scaffolding material, inducing self-assembly of lipid elements, with an exterior cationic lipid shell surrounding a core of clustered gold nanoparticles. Lipid-coated gold nanoparticles possessing a positively charged shell layer are believed to condense siRNA molecules effectively into stable nanosized polyelectrolyte complexes, enabling a gene silencing effect and efficient cellular internalization. ${ }^{79}$

To validate further the efficacy of lipid-coated gold nanoparticles in the treatment of hepatitis B, siHBV targeting viral open reading frames encoding an $\mathrm{X}$ protein was complexed with the lipid-coated gold nanoparticles to induce an antiviral response. The gene silencing effect of lipid-coated gold nanoparticles-siHBV polyelectrolyte complexes was evaluated in HBV-expressing HepG2.2.15 cells. ${ }^{79}$ After treatment with $200 \mathrm{nM}$ of lipid-coated gold nanoparticles-siHBV complexes, release of HBV surface antigen decreased markedly to $37.0 \% \pm 6.6 \%$, showing that these complexes were able to inhibit HBV replication efficiently. ${ }^{79}$ Furthermore, gold nanoparticles have been used in clinical diagnostics and therapeutics, such as cancer, tuberculosis, Alzheimer's disease, HIV, and sciatic nerve repair. ${ }^{80-84}$

\section{Bacteriophage delivery systems}

Bacteriophages are promising delivery systems, as exemplified by the Bacillus subtilis phage phi29 encoding a 117-nucleotide packaging RNA molecule. ${ }^{85}$ Packaging RNA can constitute a nanoparticle approximately $11 \mathrm{~nm}$ in size by folding into a unique and stable secondary or tertiary structure ${ }^{86}$ Further, it can encapsulate DNA into procapsids, thereby forming 10-30 nm polymers by base-pairing between two interlocking right-hand and left-hand loops. ${ }^{87} \mathrm{~A}$ packaging RNA monomer has two functional domains, ie, a double-stranded helical DNA packaging domain and an intermolecular interacting domain. ${ }^{87-91}$ Although the intermolecular regions can hardly tolerate sequence variation, the double helix allows changes in lengths and sequences without compromising the structure of packaging RNA, as long as the double helix is maintained. ${ }^{90,92,93}$ SiRNA is a double-stranded RNA helix which can replace the $3^{\prime} / 5^{\prime}$ helical region of the packaging RNA without affecting folding of siRNA and packaging RNA, or the functions of the inserted moiety ${ }^{87}$ This method can deliver siRNA to cancer cells without degradation, with a longer half-life and significant efficacy. ${ }^{87}$

Several features ${ }^{87,94,95}$ of RNA nanoparticles make nanodelivery platforms attractive:

- Two-dimensional, three-dimensional, and four-dimensional structures, which are diverse and stable

- Various biochemical/biological functions

- Metabolic stability accomplished by modification

- Ideal biodegradability, biocompatibility, and noninduction of antibodies, modularized design, and ready scale-up. ${ }^{34,96}$ 
These delivery systems can be tailored to the characteristics of focal tissues, making artificial polymer-based and virusbased vehicles dispensable. For example, based on the fact that transferrin protein receptor expression was significantly upregulated in human tumors, a $70 \mathrm{~nm}$ nanoparticle containing transferrin protein was generated and could deliver siRNA to tumor cells by systemic injection. Target gene expression can be specifically silenced by RNAi. ${ }^{97}$ Other novel immunoliposome methods can integrate nanoparticles and lymphocyte function-associated antigen-1 integrin, a molecule which is highly expressed on all leukocytes. A lymphocyte function-associated antigen-1 integrin-targeted and stabilized nanoparticle could lead to selective uptake of siRNA by T cells and macrophages, which are the principal target cells of HIV. Anti-CCR5 siRNA/lymphocyte function-associated antigen-1 integrin-targeted and stabilized nanoparticles could silence leucocyte-specific genes, thereby preventing HIV infection in BLT mice. ${ }^{98}$

\section{RNAi drugs and future opportunities}

RNAi have been tested in various fields of medicine because of their specificity, simplicity, and stability in gene silencing. ${ }^{99}$ RNAi drugs in different stages of clinical investigation are summarized in Table 1. Many obstacles remain to be overcome to bring RNAi-based therapeutics successfully to the bedside, eg, precise targeting to avoid potentially fatal off-target effects ${ }^{38}$ and overcoming the potential cytotoxicity and immunoreactivity of delivery systems. Hopefully, more indepth exploration of the above questions will expedite realization of the full potential of RNAi-based therapeutics.

\section{Acknowledgments}

This work was funded by the National Megaprojects for Key Infectious Diseases (2008ZX10003-006, 2012ZX10003-003), National Natural Science Foundation (81071316), New Century Excellent Talents in Universities

Table I RNA interference drugs in clinical trials

\begin{tabular}{|c|c|c|c|c|c|}
\hline Drug name & Diseases & Target & Phase & $\begin{array}{l}\text { Delivery } \\
\text { method }\end{array}$ & $\begin{array}{l}\text { Companyl } \\
\text { Affiliation }\end{array}$ \\
\hline Bevasiraib $^{100}$ & AMD and DME & VEGF & Phase III was stoped & Direct eye injection & Opko Health Inc \\
\hline PF-4523655 & AMD and DME & VEGF and RTP80I & II & Direct eye injection & Quark \\
\hline \multicolumn{6}{|l|}{ (REDD-I4-NP or } \\
\hline \multicolumn{6}{|l|}{ RTP-80li- I4) } \\
\hline TKM-PLKI ${ }^{102}$ & Solid tumors & PLKI & I & LNP delivery technology & Tekmira \\
\hline TKM-Ebola ${ }^{103}$ & Ebola infection & Ebola virus & 1 & LNP delivery technology & Tekmira \\
\hline ALN-RSVOI 104 & RSV infection & RSV nucleocapsids & II & Direct to lungs via inhaler & Alnylam \\
\hline QPI- $1007^{105}$ & Eye neuropathy & Capase 2 & $\mathrm{I}$ & intravitreal administration & Quark \\
\hline ALN-VSPO2 ${ }^{106}$ & Solid tumors & KSP and VEGF & 1 & $\begin{array}{l}\text { Systemic (liver) liposomal } \\
\text { conjugation }\end{array}$ & Alnylam \\
\hline \multirow[t]{2}{*}{ CALAA-0I ${ }^{107}$} & Solid tumors & RRM2 & I & Intravenous, nanoparticle & Calando \\
\hline & & & & delivery system & Pharmceuticals \\
\hline \multirow[t]{2}{*}{ TDI0I 108} & PC & Keratin K6a & I & Intradermal injection & PC Project and \\
\hline & & & & (skin) & TransDerm \\
\hline Sirna-027 & AMD & VEGF-RI & II & Direct eye injection & Allergan/Merck \\
\hline \multicolumn{6}{|l|}{$(A G N 211745)^{109}$} \\
\hline AKli-5 (I5 NP or & Acute kidney injury & P53 & ॥ & Intravenous injection & Quark \\
\hline QPI-I002) $)^{110}$ & delayed graft function & & & (systemic) & \\
\hline SPC4955"II & Hypereholesterol & Apo B & 1 & Subcutaneous injections & Santaris Pharma A/S \\
\hline \multirow[t]{2}{*}{ ALN-PCSO2 $2^{112}$} & Low density lipoprotein & PCSK9 & 1 & Intravenous (IV) infusion & Alnylam \\
\hline & cholesterol (LDL-C) & & & & \\
\hline \multirow[t]{2}{*}{ SPC500I 113} & LDL-C & PCSK9 & I & Systemic (blood) liposomal & Santaris Pharma \\
\hline & & & & conjugation & $\mathrm{A} / \mathrm{S}$ \\
\hline PRO-04020I & Hypercholesterol emia & Apo B & 1 & Lipid nanoparticles & Tekmira \\
\hline$(\text { ApoB SNALP) })^{1 / 4}$ & & & & & Pharmaceuticals \\
\hline \multirow[t]{2}{*}{ NUC B100115 } & HBV infection & HBV & I & Intravenous injection & Nastech \\
\hline & & & & (systemic) & Pharmaceytical \\
\hline BLT-HIV (rHIV7-shl- & HIV infection & HIV & I & Lentiviral (ex vivo) & Benitec Ltd \\
\hline \multicolumn{6}{|c|}{ TAR-C CR5RZ) ${ }^{116}$} \\
\hline ALN-TTROI ${ }^{117}$ & $\begin{array}{l}\text { TTR-mediated } \\
\text { amyloidosis (ATTR) }\end{array}$ & TTR & I & Lipid nanoparticles & Alnylam \\
\hline
\end{tabular}

Abbreviations: ApoB, apolipoprotein B; AMD, age-related macular degeneration; HBV, hepatitis B virus; DME, diabetic macular edema; HIV, human immunodeficiency virus; KSP, kinesin spindle protein; LNP, lipid nanoparticle; PC, pachyonychia congenita; RSV, respiratory syncytial virus; RMM2, M2 subunit of ribonucleotide reductase; vEGF, vascular endothelial growth factor; TTR, transthyretin; PLKI, polo-like kinase I; PCSK9, proprotein convertase subtilisin/kexin type 9. 
(NCET-11), Fellowship of Southwest University (kb2009010 and ky2011003), Fundamental Research Funds for the Central Universities (XDJK2009A003), and the Natural Science Foundation Project of CQ CSTC (2010BB5002).

\section{Disclosure}

The authors report no conflicts of interest in this work.

\section{References}

1. Fire A, Xu S, Montgomery MK, Kostas SA, Driver SE, Mello CC. Potent and specific genetic interference by double-stranded RNA in Caenorhabditis elegans. Nature. 1998;391(6669): 806-811.

2. Hannon GJ. RNA interference. Nature. 2002;418(6894):244-251.

3. Meister G, Tuschl T. Mechanisms of gene silencing by double-stranded RNA. Nature. 2004;431(7006):343-349.

4. Novina CD, Sharp PA. The RNAi revolution. Nature. 2004;430(6996): 161-164.

5. Pushparaj PN, Aarthi JJ, Manikandan J, Kumar SD. siRNA, miRNA, and shRNA: in vivo applications. J Dent Res. 2008;87(11):992-1003.

6. Davidson BL, McCray PB Jr. Current prospects for RNA interferencebased therapies. Nat Rev Genet. 2011;12(5):329-340.

7. Valencia-Sanchez MA, Liu J, Hannon GJ, Parker R. Control of translation and mRNA degradation by miRNAs and siRNAs. Genes Dev. 2006;20(5):515-524.

8. Bartel DP. MicroRNAs: genomics, biogenesis, mechanism, and function. Cell. 2004;116(2):281-297.

9. Lund E, Sheets MD, Imboden SB, Dahlberg JE. Limiting Ago protein restricts RNAi and microRNA biogenesis during early development in Xenopus laevis. Genes Dev. 2011;25(11):1121-1131.

10. Elbashir SM, Lendeckel W, Tuschl T. RNA interference is mediated by 21- and 22-nucleotide RNAs. Genes Dev. 2001;15(2): 188-200.

11. Zamore PD, Tuschl T, Sharp PA, Bartel DP. RNAi: double-stranded RNA directs the ATP-dependent cleavage of mRNA at 21 to 23 nucleotide intervals. Cell. 2000;101(1):25-33.

12. Lewis BP, Shih IH, Jones-Rhoades MW, Bartel DP, Burge CB. Prediction of mammalian microRNA targets. Cell. 2003;115(7):787-798.

13. Eulalio A, Huntzinger E, Izaurralde E. Getting to the root of miRNAmediated gene silencing. Cell. 2008;132(1):9-14.

14. Fabian MR, Sonenberg N, Filipowicz W. Regulation of mRNA translation and stability by microRNAs. Annu Rev Biochem. 2010;79: 351-379.

15. Bhattacharyya SN, Habermacher R, Martine U, Closs EI, Filipowicz W. Relief of microRNA-mediated translational repression in human cells subjected to stress. Cell. 2006;125(6):1111-1124.

16. Liu G, Wong-Staal F, Li QX. Recent development of RNAi in drug target discovery and validation. Drug Discov Today Technol. 2006;3(3): 293-300.

17. Elbashir SM, Harborth J, Weber K, Tuschl T. Analysis of gene function in somatic mammalian cells using small interfering RNAs. Methods. 2002;26(2):199-213.

18. Lina W, Chonggang Y. Development and applications of RNAi technology in drug research. Chin Bull Life Sci. 2007;19:199-213.

19. Reynolds A, Leake D, Boese Q, Scaringe S, Marshall WS, Khvorova A. Rational siRNA design for RNA interference. Nat Biotechnol. 2004;22(3):326-330.

20. Harborth J, Elbashir SM, Vandenburgh K, et al. Sequence, chemical, and structural variation of small interfering RNAs and short hairpin RNAs and the effect on mammalian gene silencing. Antisense Nucleic Acid Drug Dev. 2003;13(2):83-105.

21. Shirane D, Sugao K, Namiki S, Tanabe M, Iino M, Hirose K. Enzymatic production of RNAi libraries from cDNAs. Nat Genet. 2004;36(2): 190-196.
22. Herold MJ, van den Brandt J, Seibler J, Reichardt HM. Inducible and reversible gene silencing by stable integration of an shRNA-encoding lentivirus in transgenic rats. Proc Natl Acad Sci U S A. 2008;105(47): 18507-18512.

23. Li J, Huang L. Targeted delivery of RNAi therapeutics for cancer therapy. Nanomedicine (Lond). 2010;5(10):1483-1486.

24. Tuschl T. Expanding small RNA interference. Nat Biotechnol. 2002; 20(5):446-448.

25. Brummelkamp TR, Bernards R, Agami R. A system for stable expression of short interfering RNAs in mammalian cells. Science. 2002; 296(5567):550-553.

26. Tiscornia G, Singer O, Ikawa M, Verma IM. A general method for gene knockdown in mice by using lentiviral vectors expressing small interfering RNA. Proc Natl Acad Sci U SA. 2003;100(4):1844-1848.

27. Rubinson DA, Dillon CP, Kwiatkowski AV, et al. A lentivirus-based system to functionally silence genes in primary mammalian cells, stem cells and transgenic mice by RNA interference. Nat Genet. 2003;33(3): 401-406.

28. Chen Z, Stockton J, Mathis D, Benoist C. Modeling CTLA4-linked autoimmunity with RNA interference in mice. Proc Natl Acad Sci US A. 2006;103(44):16400-16405.

29. Matsukura S, Jones PA, Takai D. Establishment of conditional vectors for hairpin siRNA knockdowns. Nucleic Acids Res. 2003;31(15):e77.

30. Sheng Y, Lin CC, Yue J, et al. Generation and characterization of a Tet-On (rtTA-M2) transgenic rat. BMC Dev Biol. 2010;10:17.

31. Seibler J, Kleinridders A, Küter-Luks B, Niehaves S, Brüning JC, Schwenk F. Reversible gene knockdown in mice using a tight, inducible shRNA expression system. Nucleic Acids Res. 2007;35(7):e54.

32. Anastassiadis K, Kim J, Daigle N, Sprengel R, Schöler HR, Stewart AF. A predictable ligand regulated expression strategy for stably integrated transgenes in mammalian cells in culture. Gene. 2002;298(2):159-172.

33. Szymczak AL, Vignali DA. Development of 2A peptide-based strategies in the design of multicistronic vectors. Expert Opin Biol Ther. 2005;5(5):627-638.

34. Abdelmawla S, Guo S, Zhang L, et al. Pharmacological characterization of chemically synthesized monomeric phi29 pRNA nanoparticles for systemic delivery. Mol Ther. 2011;19(7):1312-1322.

35. Woodle MC, Lu PY. Nanoparticles deliver RNAi therapy. Mater Today. 2005;8(8 Suppl 1):34-41.

36. Allen TM, Cullis PR. Drug delivery systems: entering the mainstream. Science. 2004;303(5665):1818-1822.

37. van den Boorn JG, Schlee M, Coch C, Hartmann G. SiRNA delivery with exosome nanoparticles. Nat Biotechnol. 2011;29(4):325-326.

38. Lares MR, Rossi JJ, Ouellet DL. RNAi and small interfering RNAs in human disease therapeutic applications. Trends Biotechnol. 2010; 28(11):570-579.

39. Sutton D, Kim S, Shuai X, et al. Efficient suppression of secretory clusterin levels by polymer-siRNA nanocomplexes enhances ionizing radiation lethality in human MCF-7 breast cancer cells in vitro. Int $J$ Nanomedicine. 2006;1(2):155-162.

40. Wu Y, Wang W, Chen Y, et al. The investigation of polymer-siRNA nanoparticle for gene therapy of gastric cancer in vitro. Int $J$ Nanomedicine. 2010;5:129-136.

41. Yamamichi K, Uehara Y, Kitamura N, Nakane Y, Hioki K. Increased expression of CD44v6 mRNA significantly correlates with distant metastasis and poor prognosis in gastric cancer. Int J Cancer. 1998; 79(3):256-262.

42. Kurozumi K, Nishida T, Nakao K, Nakahara M, Tsujimoto M. Expression of CD44 variant 6 and lymphatic invasion: importance to lymph node metastasis in gastric cancer. World J Surg. 1998;22(8):853-857.

43. Miyoshi H, Blomer U, Takahashi M, Gage FH, Verma IM. Development of a self-inactivating lentivirus vector. J Virol. 1998;72(10): $8150-8157$.

44. VandenDriessche T, Thorrez L, Naldini L, et al. Lentiviral vectors containing the human immunodeficiency virus type- 1 central polypurine tract can efficiently transduce nondividing hepatocytes and antigenpresenting cells in vivo. Blood. 2002;100(3):813-822. 
45. Hacein-Bey-Abina S, Von Kalle C, Schmidt M, et al. LMO2-associated clonal $\mathrm{T}$ cell proliferation in two patients after gene therapy for SCIDX1. Science. 2003;302(5644):415-419.

46. Hannon GJ, Rossi JJ. Unlocking the potential of the human genome with RNA interference. Nature. 2004;431(7006):371-378.

47. Raoul C, Abbas-Terki T, Bensadoun JC, et al. Lentiviral-mediated silencing of SOD1 through RNA interference retards disease onset and progression in a mouse model of ALS. Nat Med. 2005;11(43):423-428.

48. McKinley MP, Bolton DC, Prusiner SB. A protease-resistant protein is a structural component of the Scrapie prion. Cell. 1983;35(1):57-62.

49. Bolton D, McKinley M, Prusiner S. Identification of a protein that purifies with the scrapie prion. Science. 1982;218(4579):1309-1311.

50. Giese A, Brown DR, Groschup MH, Feldmann C, Haist I, Kretzschmar HA. Role of microglia in neuronal cell death in prion disease. Brain Pathol. 1998;8(3):449-457.

51. Bueler H, Raeber A, Sailer A, Fischer M, Aguzzi A, Weissmann C. High prion and PrPSc levels but delayed onset of disease in scrapieinoculated mice heterozygous for a disrupted PrP gene. Mol Med. 1994; 1(1):19-30

52. Pfeifer A, Eigenbrod S, Al-Khadra S, et al. Lentivector-mediated RNAi efficiently suppresses prion protein and prolongs survival of scrapieinfected mice. J Clin Invest. 2006;116(12):3204-3210.

53. Mallucci G, Dickinson A, Linehan J, Klöhn PC, Brandner S, Collinge J. Depleting neuronal PrP in prion infection prevents disease and reverses spongiosis. Science. 2003;302(5646):871-874.

54. Gallozzi M, Chapuis J, Le Provost F, et al. Prnp knockdown in transgenic mice using RNA interference. Transgenic Res. 2008;17(5):783-791.

55. Pulford B, Reim N, Bell A, et al. Liposome-siRNA-peptide complexes cross the blood-brain barrier and significantly decrease PrP on neuronal cells and PrP in infected cell cultures. PLoS One. 2010;5(6):e11085.

56. Berger EA, Murphy PM, Farber JM. Chemokine receptors as HIV-1 coreceptors: roles in viral entry, tropism, and disease. Ann Rev Immunol. 1999;17(1):657-700.

57. Moore JP, Trkola A, Dragic T. Co-receptors for HIV-1 entry. Curr Opin Immunol. 1997;9(4):551-562.

58. Mosier D. Virus and target cell evolution in human immunodeficiency virus type 1 infection. Immunol Res. 2000;21(2):253-258.

59. Simmons G, Reeves JD, Hibbitts S, et al. Co-receptor use by HIV and inhibition of HIV infection by chemokine receptor ligands. Immunol Rev. 2000;177(1):112-126.

60. O'Brien SJ, Nelson GW. Human genes that limit AIDS. Nat Genet. 2004;36(6):565-574.

61. Smith MW, Dean M, Carrington M, et al. Contrasting genetic influence of CCR 2 and CCR 5 variants on HIV-1 infection and disease progression. Hemophilia Growth and Development Study (HGDS), Multicenter AIDS Cohort Study (MACS), Multicenter Hemophilia Cohort Study (MHCS), San Francisco City Cohort (SFCC), ALIVE Study. Science. 1997;277(5328):959-965.

62. Shimizu S, Hong P, Arumugam B, et al. A highly efficient short hairpin RNA potently down-regulates CCR5 expression in systemic lymphoid organs in the hu-BLT mouse model. Blood. 2010;115(8):1534-1544.

63. Zhang S, Zhao B, Jiang H, Wang B, Ma B. Cationic lipids and polymers mediated vectors for delivery of siRNA. J Control Release. 2007;123(1):1-10.

64. Andersen MO, Howard KA, Paludan SR, Besenbacher F, Kjems J. Delivery of siRNA from lyophilized polymeric surfaces. Biomaterials. 2008;29(4):506-512.

65 Kumar P, Wu H, McBride JL, et al. Transvascular delivery of small interfering RNA to the central nervous system. Nature. 2007;448(7149): 39-43.

66. Lafon M. Rabies virus receptors. J Neurovirol. 2005;11(1):82-87.

67. Morrissey DV, Lockridge JA, Shaw L, et al. Potent and persistent in vivo anti-HBV activity of chemically modified siRNAs. Nat Biotechnol. 2005;23(8):1002-1007.

68. Richards D, Ivanisevic A. Inorganic material coatings and their effect on cytotoxicity. Chem Soc Rev. 2012;41(6):2052-2060.
69. Rippel RA, Seifalian AM. Gold revolution - gold nanoparticles for modern medicine and surgery. J Nanosci Nanotechnol. 2011;11(5): 3740-3748.

70. Ghosh P, Han G, De M, Kim CK, Rotello VM. Gold nanoparticles in delivery applications. Adv Drug Deliv Rev. 2008;60(11):1307-1315.

71. Guo S, Huang Y, Jiang Q, et al. Enhanced gene delivery and siRNA silencing by gold nanoparticles coated with charge-reversal polyelectrolyte. ACS Nano. 2010;4(9):5505-5511.

72. Chen AM, Taratula O, Wei D, et al. Labile catalytic packaging of DNA/ siRNA: control of gold nanoparticles "out" of DNA/siRNA complexes. ACS Nano. 2010;4(7):3679-3688.

73. Thomas M, Klibanov AM. Conjugation to gold nanoparticles enhances polyethylenimine's transfer of plasmid DNA into mammalian cells. Proc Natl Acad Sci U S A. 2003;100(16):9138-9143.

74. Rosi NL, Giljohann DA, Thaxton CS, Lytton-Jean AKR, Han MS, Mirkin CA. Oligonucleotide-modified gold nanoparticles for intracellular gene regulation. Science. 2006;312(5776):1027-1030.

75. Elbakry A, Zaky A, Liebl R, Rachel R, Goepferich A, Breunig M. Layer-by-layer assembled gold nanoparticles for siRNA delivery. Nano Lett. 2009;9(5):2059-2064.

76. Lee JS, Green JJ, Love KT, Sunshine J, Langer R, Anderson DG. Gold, poly(beta-amino ester) nanoparticles for small interfering RNA delivery. Nano Lett. 2009;9(6):2402-2406.

77. Song WJ, Du JZ, Sun TM, Zhang PZ, Wang J. Gold nanoparticles capped with polyethyleneimine for enhanced siRNA delivery. Small. 2010;6(2):239-246.

78. Zuckerman JE, Choi CHJ, Han H, Davis ME. Polycation-siRNA nanoparticles can disassemble at the kidney glomerular basement membrane. Proc Natl Acad Sci U S A. 2012;109(8):3137-3142.

79. Kong W, Bae K, Jo S, Kim J, Park T. Cationic lipid-coated gold nanoparticles as efficient and non-cytotoxic intracellular siRNA delivery vehicles. Pharm Res. 2012;29(2):362-374.

80. Sokolov K, Follen M, Aaron J, et al. Real-time vital optical imaging of precancer using anti-epidermal growth factor receptor antibodies conjugated to gold nanoparticles. Cancer Res. 2003;63(9):1999-2004.

81. Xi D, Luo X, Ning Q, Lu Q, Yao K, Liu Z. The detection of HBV DNA with gold nanoparticle gene probes. Journal of Nanjing Medical University. 2007;21(4):207-212.

82. Baptista PV, Koziol-Montewka M, Paluch-Oles J, Doria G, Franco R. Gold nanoparticle probe-based assay for rapid and direct detection of Mycobacterium tuberculosis DNA in clinical samples. Clin Chem. 2006;52(7):1433-1434.

83. Georganopoulou DG, Chang L, Nam JM, et al. Nanoparticle-based detection in cerebral spinal fluid of a soluble pathogenic biomarker for Alzheimer's disease. Proc Natl Acad Sci U S A. 2005;102(7): 2273-2276

84. Mahmoud KA, Luong JHT. Impedance method for detecting HIV-1 protease and screening for its inhibitors using ferrocene-peptide conjugate/Au nanoparticle/single-walled carbon nanotube modified electrode. Anal Chem. 2008;80(18):7056-7062.

85. Guo P, Erickson S, Anderson D. A small viral RNA is required for in vitro packaging of bacteriophage phi 29 DNA. Science. 1987;236(4802): 690-694.

86. Hoeprich S, Guo P. Computer modeling of three-dimensional structure of DNA-packaging RNA (pRNA) monomer, dimer, and hexamer of Phi29 DNA packaging motor. J Biol Chem. 2002;277(23): 20794-20803.

87. Khaled A, Guo S, Li F, Guo P. Controllable self-assembly of nanoparticles for specific delivery of multiple therapeutic molecules to cancer cells using RNA nanotechnology. Nano Lett. 2005;5(9): 1797-1808.

88. Chen C, Sheng S, Shao Z, Guo P. A dimer as a building block in assembling RNA. J Biol Chem. 2000;275(23):17510-17516.

89. Zhang C, Lee CS, Guo P. The proximate $5^{\prime}$ and $3^{\prime}$ ends of the 120 -base viral RNA (pRNA) are crucial for the packaging of bacteriophage Ø29 DNA. Virology. 1994;201(1):77-85. 
90. Garver K, Guo P. Boundary of pRNA functional domains and minimum pRNA sequence requirement for specific connector binding and DNA packaging of phage phi29. RNA. 1997;3(9):1068-1079.

91. Reid RJ, Bodley JW, Anderson D. Characterization of the proheadpRNA interaction of bacteriophage phi 29. J Biol Chem. 1994;269(7): 5157-5162.

92. Chen C, Zhang C, Guo P. Sequence requirement for hand-in-hand interaction in formation of RNA dimers and hexamers to gear phi29 DNA translocation motor. RNA. 1999;5(6):805-818.

93. Zhang C, Trottier M, Guo P. Circularly permuted viral pRNA active and specific in the packaging of bacteriophage $\varphi 29$ DNA. Virology. 1995;207(2):442-451.

94. Guo S, Tschammer N, Mohammed S, Guo P. Specific delivery of therapeutic RNAs to cancer cells via the dimerization mechanism of phi29 motor pRNA. Hum Gene Ther. 2005;16(9):1097-1109.

95. Guo S, Huang F, Guo P. Construction of folate-conjugated pRNA of bacteriophage phi29 DNA packaging motor for delivery of chimeric siRNA to nasopharyngeal carcinoma cells. Gene Ther. 2006;13(10):814-820.

96. Liu J, Guo S, Cinier M, et al. Fabrication of stable and RNase-resistant RNA nanoparticles active in gearing the nanomotors for viral DNA packaging. ACS Nano. 2010;5(1):237-246.

97. Davis ME, Zuckerman JE, Choi CHJ, et al. Evidence of RNAi in humans from systemically administered siRNA via targeted nanoparticles. Nature. 2010;464(7291):1067-1070.

98. Kim SS, Peer D, Kumar P, et al. RNAi-mediated CCR5 silencing by LFA-1-targeted nanoparticles prevents HIV infection in BLT mice. Mol Ther. 2010;18(2):370-376.

99. Xinping L. Applications of RNA interference technology to drug study. Chinese Pharmacological Bulletin. 2005;21(4):400-403.

100. TheFreeLibrary.com [homepage on the Internet]. OPKO Health Announces Update on Phase III Clinical Trial of Bevasiranib. Pennsylvania: Farlex, Inc.; c 2012 [updated 2009 May 6; cited 2012 Apr 10]. Available from: http://www.thefreelibrary.com/OPKO+Health+Ann ounces+Update+on+Phase+III+Clinical+Trial+of...-a0195014938. Accessed Jun 25, 2012

101. Quarkpharma.com [homepage on the Internet]. Quark Pharmaceuticals Presented At ARVO Data Showing That PF-04523655 Enters Retinal Cells And Elicits Its Pharmacologic Effect Via Target Gene KnockDown Without Activating TLR3. California: Quark Pharmaceuticals, Inc.; c 2007 [updated 2009 May 11; cited 2012 Apr 10]. Available from: http://www.quarkpharma.com/qbi-en/newslist/arvo/. Accessed Jun 25, 2012.

102. Tekmirapharm.com [homepage on the Internet]. Tekmira Provides Corporate Update and Announces First Quarter 2012 Results. British Columbia: Tekmira Pharmaceuticals Corp.; c 2012 [updated 2012 May 15; cited 2012 Apr 10]. Available from: http://investor.tekmirapharm. com/releasedetail.cfm?releaseid=673804. Accessed Jun 22, 2012.

103. Tekmirapharm.com [homepage on the Internet]. Tekmira Announces Initiation of TKM-Ebola Phase 1 Clinical Trial British Columbia: Tekmira Pharmaceuticals Corp.; c 2012 [updated 2012 Feb 8; cited 2012 Apr 10]. Available from: http://files.shareholder.com/downloads/ ABEA-50QJTB/1754071349x0x541056/d731bed8-39f3-4fe2-a962c86e2f72e681/TKMR_News_2012_2_8_General_Releases.pdf. Accessed Jun 24, 2012.

104. Pharmaceuticals A. Phase $2 \mathrm{~b}$ Study of ALN-RSV01 in Lung Transplant Patients Infected With Respiratory Syncytial Virus (RSV). In: ClinicalTrials.gov [website on the Internet]. Bethesda, MD: US National Library of Medicine; 2012 [updated 2012 May 30]. Available from: http:// clinicaltrials.gov/ct2/show/NCT01065935?term=Alnylam\&rank=5. ClinicalTrials.gov Identifier: NCT01065935. Accessed Jul 11, 2012.

105 Quarkpharma.com [homepage on the Internet]. Quark Pharmaceuticals Reports Favorable Interim Results from Phase I Clinical Study of QPI1007 California: Quark Pharmaceuticals, Inc.; c 2007 [updated 2012 Jan 4; cited 2012 Apr 10]. Available from: http://www.quarkpharma. com/qbi-en/newslist/clinicalstudyqpi-1007/. Accessed Jun 21, 2012.
106. Pharmaceuticals A. Dose Escalation Trial to Evaluate the Safety, Tolerability, Pharmacokinetics and Pharmacodynamics of Intravenous ALN-VSP02 In Patients With Advanced Solid Tumors With Liver Involvement. In: ClinicalTrials.gov [website on the Internet]. Bethesda, MD: US National Library of Medicine; 2011 [updated 2011 Aug 23]. Available from: http:/clinicaltrials.gov/ct2/show/ NCT00882180?term $=$ Alnylam\&rank=3. ClinicalTrials.gov Identifier: NCT00882180. Accessed Jul 11, 2012.

107. Calando.com [homepage on the Internet]. Arrowhead Research Subsidiary, Calando Pharmaceuticals, Provides First Proof of RNA Interference in Humans with Systemically Administered siRNA Therapeutic; Clinical Trial Results Published in Nature California: Calando Pharmaceuticals; c 2012 [updated 2010 Mar 22; cited 2012 Apr 11]. Available from: http://www.calandopharma.com/ newspdfs/NR--Calando_data--3-22-10_final.pdf. Accessed Jun 19, 2012.

108. Project PC. Study of TD101, a Small Interfering RNA (siRNA) Designed for Treatment of Pachyonychia Congenita. In: ClinicalTrials. gov [website on the Internet]. Bethesda, MD: US National Library of Medicine; 2008 [updated 2008 Nov 18]. Available from: http://clinicaltrials.gov/ct2/show/NCT00716014. ClinicalTrials.gov Identifier: NCT00716014. Accessed Jul 11, 2012.

109. Genomeweb.com [homepage on the Internet]. Allergan Drops Development of siRNA Rx for AMD on Poor Phase II Data. New York: GenomeWeb LLC.; c 2012 [updated 2009 May 28; cited 2012 Apr 11]. Available from: http://www.genomeweb.com/rnai/allergandrops-development-sirna-rx-amd-poor-phase-ii-data. Accessed June 21, 2012.

110. Quarkpharma.com [homepage on the Internet]. QPI-1002. California: Quark Pharmaceuticals, Inc.; c 2007 [updated 2010 Aug 18; cited 2012 Apr 10]. Available from: http://www.quarkpharma.com/qbi-en/ products/QPI-1002da/. Accessed Jun 15, 2012.

111. TheFreeLibrary.com [homepage on the Internet]. Santaris Pharma A/S Advances a Second Drug From Its Cardiometabolic Program, SPC4955, Inhibiting apoB, into Phase 1 Clinical Trials for the Treatment of High Cholesterol. Pennsylvania: Farlex, Inc.; c 2012 [updated 2011 May 11; cited 2012 Apr 10]. Available from: http:/www.thefreelibrary.com/Santaris + Pharma $+\mathrm{A} \% 2 \mathrm{fS}+$ Advances $+\mathrm{a}+$ Second + Drug $+\mathrm{F}$ rom+Its+Cardiometabolic...-a0256048995. Accessed May 11, 2012.

112. Pharmaceuticals A. Trial to Evaluate Safety and Tolerability of ALNPCS02 in Subjects With Elevated LDL-Cholesterol (LDL-C). In: ClinicalTrials.gov [website on the Internet]. Bethesda, MD: US National Library of Medicine; 2012 [updated 2012 Apr 20]. Available from: http:// clinicaltrials.gov/ct2/show/NCT01437059?term=PCS02\&rank=1. ClinicalTrials.gov Identifier: NCT01437059. Accessed Jul 11, 2012.

113. Santaris.com [homepage on the Internet]. Santaris Pharma A/S advances new cholesterol-lowering drug, SPC5001 inhibiting exciting new target PCSK9, into Phase 1 clinical trials for the treatment of high cholesterol. San Diego: Santaris Pharma A/S; c 2011 [updated 2011 May 4; cited 2012 Apr 9]. Available from: http://www.santaris. com/news/2011/05/04/santaris-pharma-advances-new-cholesterollowering-drug-spc5001-inhibiting-exciting-n. Accessed Jun 25, 2012.

114. Tekmirapharm.com [homepage on the Internet]. Tekmira Pharmaceuticals Completes ApoB SNALP Phase 1 Clinical Trial. British Columbia: Tekmira Pharmaceuticals Corp.; c 2012 [updated 2010 Jan 7; cited 2012 Apr 10]. Available from: http://files.shareholder.com/ downloads/ABEA-50QJTB/1754071349x0x425312/9b404e8f-82e248a8-ba61-71328539afd9/TKM_News_2010_1_7_General_Releases. pdf. Accessed Jun 29, 2012.

115. Giiresearch.com [homepage on the Internet]. Top Companies and Products in the RNA/DNA Therapy Products Market Forecasts: The challenge of turning technology into therapy. Kawasaki: Global Information, Inc.; c 1997-2007 [updated 2011 Aug 12; cited 2012 Apr 11] Available from: http://www.giiresearch.com/report/kt55538-therapyprod.html. Accessed Jun 26, 2012. 
116. Abnnewswire.net [homepage on the Internet]. rHIV7-shI-TARCCR5RZ. New York: ABN Newswire; c 2012 [updated 2010 Nov 1; cited 2012 Apr 11]. Available from: http://www.abnnewswire.net/ search.asp?cp=utf-8\&lang=_c\&site=press_c\&client=press-searchcs\&output=xml_no_dtd\&proxystylesheet=press-search-cs\&proxyr eload $=1 \&$ filter $=$ p\&getfields $=* \&$ way $=$ abn $\&$ way $=$ web $\& q u=$ rHIV7shI-TAR-CCR5RZ\&stype=press_c\&image $2 . x=33 \&$ image $2 . y=10$. Accessed Jun 18, 2012.
117. Pharmaceuticals A. Trial to Evaluate Safety and Tolerability of ALN-TTR01 in Transthyretin (TTR) Amyloidosis. In: ClinicalTrials. gov [website on the Internet]. Bethesda, MD: US National Library of Medicine; 2012 [updated 2012 May 23]. Available from: http:// clinicaltrials.gov/ct2/show/NCT01148953?term=Alnylam\&rank=4. ClinicalTrials.gov Identifier: NCT01148953. Accessed Jul 11, 2012.

\section{Publish your work in this journal}

The International Journal of Nanomedicine is an international, peerreviewed journal focusing on the application of nanotechnology in diagnostics, therapeutics, and drug delivery systems throughout the biomedical field. This journal is indexed on PubMed Central, MedLine, CAS, SciSearch $\AA$, Current Contents ${ }^{\circledR} /$ Clinical Medicine,
Journal Citation Reports/Science Edition, EMBase, Scopus and the Elsevier Bibliographic databases. The manuscript management system is completely online and includes a very quick and fair peer-review system, which is all easy to use. Visit http://www.dovepress.com/ testimonials.php to read real quotes from published authors. 